\title{
Assessing the Empirical Evidence of Attitude Intention Relationship in the Purchase of Energy Efficient Vehicle
}

\author{
${ }^{1}$ Vahe Andonians Salmas and ${ }^{2}$ Michael Gruning \\ 1,2 Master's in management Analytics, Mannheim Business School, Germany \\ ${ }^{2}$ michaelgr@aol.com
}

\author{
Article Info \\ Journal of Journal of Enterprise and Business Intelligence (http://anapub.co.ke/journals/jebi/jebi.html) \\ Doi: https://doi.org/10.53759/5181/JEBI202202001 \\ Received 05 May 2021; Revised form 30 July 2021; Accepted 25 September 2021. \\ Available online 05 January 2022. \\ (C2022 Published by AnaPub Publications.
}

\begin{abstract}
Despite warnings about limited fossil fuel as well as the detrimental impacts of burning such fuels, the number of conventionally fueled vehicles in use is growing worldwide. While energy efficient vehicles (EEVs) produce far less emissions and provide power from renewable sources, EEVs are yet to get full acceptance from the local market and the penetration rate is still low. In Malaysia, thesales trend shows that there is a low level of EEV purchased, where energy efficient vehicle only owned 3 percent of market share in Malaysian automotive industry. To fill this gap, this study focuses to examine the relationship between consumers' attitude towards EEV and their intention to purchase energy efficient vehicle. Data was collected using quantitative approach through mall intercept survey method at ten selected malls in Peninsular Malaysia. Respondents were intercepted at the entrance of the mall and were invited to take part in the survey. The complete process of data collection took five months and comprised a total of 515 respondents. The hypothesis in the present study was tested using Partial Least Squares (PLS). The analysis revealed a positive relationship exists between consumers' attitudes on EEVs and intention to purchase EEVs. The present study provides recommendations, limitations, and suggestions for future study.
\end{abstract}

Keywords - Energy efficient vehicle; Attitude; Purchase intention; Consumer purchase behaviour.

\section{INTRODUCTION}

Despite the growth in Malaysian automotive industry from year to year, there are many environmental effects associated with this industry. [1] in their studies reported that amongst others, transportation is the main cause of atmospheric pollutions, which contributes to problems such as noise and air pollution, environmental degradation and environmental change as well as rise in sea water level.

The increasing demand for petrol and scarce of resources has increases concern among car manufacturers to create innovative solutions toward better environmental protection by reducing carbon dioxide emission and petrol consumption. Energy Efficient Vehicle (EEV) has been marketed as an impressive and innovative vehicle in automotive industry. Malaysia Automotive Institute (MAI) describes EEV as a category of vehicle that fulfills a set of specification in terms of carbon emission level $(\mathrm{g} / \mathrm{km})$ and fuel consumption $(1 / 100 \mathrm{~km})$. EEV comprises of plugin hybrid electric vehicle (PHEV), fuel-efficient internal combustion engine vehicle (ICE), electric vehicle (EV), and alternative fuel vehicles such as Biodiesel, Ethanol, Hydrogen and Fuel Cell, Compressed Natural Gas (CNG), and Liquefied Petroleum Gas (LPG) [2].

Statement made by [2] indicates that Malaysia aims to achieve 40 percent reduction in greenhouse carbon dioxide emissions by 2020 [3]. To support this aim, Ministry of Transport (MOT) collaborate with International Trade Ministry of Industry (MITI) and Department of Energy, Green Technology and Water (MEGTW) to develop and design the facilities and action plan for the usage of EEV in Malaysian context. Thus, in the National Automotive Policies 2014, the mission to position Malaysia as a regional automobile center for energy efficient vehicle or green vehicles has been included as one of the key areas [4].

Among the available models for EVV in Malaysia is Nissan Leaf, which has a substantial gain in quality and performance whereat $110 \mathrm{~kW}(148 \mathrm{hp})$ and $320 \mathrm{NM}$, the electric motor in this car produces power and torque more than $38 \%$ and $26 \%$ respectively. Renault's Zoe contains a fully-electric powertrain, with greater-capacity $40 \mathrm{kWh}$ lithium-ion battery that enhances its range on the New European Driving Cycle (NEDC) from $195 \mathrm{~km}$ to $378 \mathrm{~km}$. Its single synchronous electric motor yields $87 \mathrm{hp}$ between 3,000 to 11,300 rpm and $220 \mathrm{Nm}$ of torque from 250 to 
2,500 rpm. Tesla Model S operates at $410 \mathrm{~km}$ operating range, a $0-100 \mathrm{~km} / \mathrm{h}$ time of 3.3 seconds, and a $249 \mathrm{~km} / \mathrm{h}$ top speed. Another category of EVV becoming popular in Malaysia is the plug-in hybrid electric vehicle (PHEV). The models available include BMW330e, Mercedes Benz C350e, and Volvo S90 T8, Hyundai Ioniq, Honda Jazz 1.5 hybrid and Nissan Serena S-hybrid. More of this category of vehicles will be launched in Malaysian market in the near future [5].

The National Automotive Policy highlighted on the important of automobile manufacturing process to produce safe, good quality, reliable and environmentally friendly vehicles at an affordable price. With the advancement in technology, automobile manufacturers should alert of the effects of vehicle production process and they should utilize technology to diminish the greenhouse gas emissions by focusing on research and development of environmentally friendly vehicles [6]. Apart from that, Malaysia Automotive Institute (MAI) reported that Malaysia is moving forward to be a green hub in this region and will start launching environmentally friendly vehicles in 2025, indicating full penetration of environmentally friendly vehicles in Malaysia. MAI predicted that in the next five years more and more energy efficient vehicle latest model will be marketed locally [7].

When EEV becomes customer's choice, it can help to rise the responsibility of Malaysian consumers to become more environmentally responsible in their consumption, appreciative the environment and maintain sustainability of future [8]. Although EEV is one of the options to reduce greenhouse emission that contributes to environmental climate change and also scarcity of resources, yet the percentage of consumption and purchase rate of EEV is very small and only a few automobile manufacturers introduce EEV at a limited volume in local market [9].

Nowadays, adopting environmentally friendly marketing practices has become a trend to many businesses worldwide, but for Asian countries, including Malaysia, the trend is not well adopted [10]. Because of limited experience, Malaysia's environmentally friendly practice has directly come from the West [11]. On top of that, there is scarce of studies that focuses on the environmentally friendly purchase behaviour among consumers in Malaysia and this has inspired more studies be conducted to bridge the gap, mainly from the perspective of high-priced, uncommon, and high-risk category of product such as car purchase [12]. Reiterated [13] that in the market for EEV, consumers are quite reluctant to accept new innovation, a reticence which impedes the process of commercialization. In the case where consumers are hesitant to adopt innovations, manufacturers will be hesitant to supply them. Without manufacturers and consumers working together, technological innovations will not be commercialized at a speedy rate.

Referring to the above discussion, it signifies that consumers play a crucial role to encourage the adoption of green purchase behaviour. In Malaysian setting, the automobile industry is among the industries that associated with the rising of consumer consciousness on environmental issues. We hope the present study cashed lights on the consumer's inclination towards EEV. Hence, the present study hopes to offer valuable input to the Malaysian automobile industry to identify factors that influence willingness to purchase EEV and to assist them to promote EEV consumption in the local market.

\section{LITERATURE REVIEW}

Green purchase intention represents consumer's readiness to purchase green products or services for the benefits of environment or to express the concern towards environment [14]. According to [15] green purchase intention is conceptualized as the probability and willingness of a person to give preference to products with eco-friendly features over other conventional products in their purchase decisions. In the attitude-behaviour relationship, intention is a function of the level of effort needed to carry out a behaviour. In contrast to general intention, green purchase intention is a new concept used to refer to the intention to purchase a product that is considered green [16]. Generally, green purchase intention describes an individual who plans to purchase a product that is environmentally friendly.

Theory of Reasoned Action (TRA) is one of the main theories used in research on green purchase behaviour [17]. This theory was developed by [18]. TRA is applied to contend that consumers' attitude and social influence towards the issue of environmental problems can influence their behaviour and action towards the purchase of green purchase [19]. Support for the TRA model has been considerably discussed in the consumer behaviour literature to predict consumers' intention and actual behaviour [20].

There are many researchers who conducted studies on purchase intention. For instance, [4] applied the Theory of Planned Behaviour (TPB) model to predict the intention to purchase green and sustainable houses of Malaysians and found that attitude, perceived behavioural control, and perceived self-identity had positive causal effects on behavioural intention to purchase. On the [7] applied four basic concepts of green market (green perceived value, perceived risk, trust, and purchase intention) and discovered that green perceived risk was negatively associated with green perceived trust and green purchase intention [8]. 
Generally, empirical literature had proved the intensity of purchase intention as a proxy measure of future behaviour [5]. The reasons for using purchase intention as a single dependent variable are firstly, purchase intention is inclined to be the best single predictor of actual behaviour [9] and secondly, predicting purchase intention is much simpler compared to predicting actual purchase behaviour [5]. [3] mentioned that intention has a direct influence on actual behavior, and when a certain degree of intention has been achieved, it will produce the strongest prediction of behavior. Moreover, measuring actual adoption is not easy and slightly hard to achieve [9]. As been mentioned by [15], EEVs are long-lasting vehicles that are characterized by expensive price and with new innovation. Therefore, they are not purchased regularly. This definition allows us to concentrate on consumers' purchase intention rather than focuses on the actual purchase.

The influence of consumer's attitude toward intention to purchase EEV

Attitude has always been highlighted as a crucial predictor of behavioural intention and actual behaviour in green consumer psychology studies. It is a learned predilection to react in a constantly favourable or unfavourable manner towards an item [9]. Attitudes towards a behaviour is defined as the measurement of an individual's evaluation and expression either considering about someone or something which is replicated in an individual's behavior [12].

Some researchers had established the appropriateness of this phenomenon with purchase intention and actual purchase behaviour of green products. Hence, it was found that people with a strong positive attitude towards green products such as energy efficient vehicle have higher level of commitment in their purchase decision to buy such category of products.

\section{METHODOLOGY}

The research design in the present study is quantitative approach, where questionnaire has been used to gather information on consumers' intention to purchase EEV from five major cities in Malaysia. The population of this study comprised of consumers aged 25 years and above. The reason for targeting consumers aged 25 years and above is because the context of this study involved high-end product category, so the target consumers is appropriate since they earned high disposable income and they demand a car as transportation. Furthermore, this group of consumers are more concern on performance, value, quality, and risk as main considerations to measure when they intend to purchase a car [18]. Using mall intercept survey method, ten malls were chosen (two in each cities). The respondents were intercepted at the entrance of the mall and were invited to take part in this survey. In order to get a varied mix of respondents and to minimize the issue of bias, different periods of time in a day were used to distribute the questionnaires. The data collection process took 5 months to complete and a total of 515 respondents participated, where 42 per cent were female and 58 per cent were male. Among the total respondents, 15 per cent of them were at the age between 25-30 years, 25 per cent were between 31-40 years, 46 per cent between $41-50$ years, and the remaining 14 percent were above the age of 50 years.

The instruments to measure attitude and intention in the present study were adapted from previous studies. Iintention to purchase EEV is operationalised as consumers' readiness and willingness to make a purchase of energy efficient vehicle. This construct consisted of six (6) items on a 5-point Likert scale adopted from [20]. Understanding consumers' attitude is crucial in relation to their intention to purchase EEV. It is important to recognise the connection between consumers' attitude and their concern for the environment in the purchase of an environmentally friendly product like EEV. Hence, consumer's attitude toward the EEV is operationalised as consumers favourable or unfavourable response to EEV.

\section{DATA ANALYSIS}

The hypothesis in the present study was tested using Partial Least Squares (PLS). Analysis using PLS was carried out via two steps, i.e. measurement model and structural model [16]. The measurement model involves the evaluation of reliability and validity of the items. For the structural model, it involves examining the relationships amongst the constructs and also testing the hypothesis. The reason of using Partial least squares (PLS) to run the measurement and structural model analysis is because PLS does not require a big sample size, no need for a normal distribution of data, and is useful for prediction [6].

\section{Assessing the measurement model}

Before testing the structural relationship between two variables, it is required to check the reliability and validity of the outer model in terms of item reliability, and construct reliability and validity [3]. As shown in Table 1, the loading of each item, the value of Cronbach's Alpha, average variance extracted of each construct and the value of 
composite reliability are higher than 0.70 , and 0.50 respectively. Thus, the reliability and convergent validity of the constructs have been achieved [20].

Table 1. Reliability and Convergent Validity of the Constructs

\begin{tabular}{|c|c|c|c|c|c|c|c|c|c|c|c|}
\hline Construct & Item & FL & $\alpha$ & $\mathrm{CR}$ & AVE & Construct & Item & FL & $\alpha$ & $\mathrm{CR}$ & AVE \\
\hline \multirow[t]{11}{*}{ ATT } & Att1 & 0.798 & 0.925 & 0.937 & 0.575 & INT & Int1 & 0.754 & 0.828 & 0.875 & 0.539 \\
\hline & Att2 & 0.765 & & & & & Int2 & 0.662 & & & \\
\hline & Att3 & 0.815 & & & & & Int3 & 0.654 & & & \\
\hline & Att4 & 0.857 & & & & & Int4 & 0.747 & & & \\
\hline & Att5 & 0.798 & & & & & Int5 & 0.814 & & & \\
\hline & Att6 & 0.804 & & & & & Int6 & 0.762 & & & \\
\hline & Att7 & 0.800 & & & & & & & & & \\
\hline & Att8 & 0.723 & & & & & & & & & \\
\hline & Att9 & 0.640 & & & & & & & & & \\
\hline & Att10 & 0.654 & & & & & & & & & \\
\hline & Att11 & 0.651 & & & & & & & & & \\
\hline
\end{tabular}

Note: $\alpha=$ Cronbach's Alpha; FL=Factor Loading; CR=Composite Reliability; AVE=Average Variance Extracted; ATT=Attitude; INT=Intention to Purchase

Additionally, the discriminant validity for both constructs has been examined using Heterotrait-Monotrait (HTMT) method as recommended. As depicted in Table 2 below, the observed correlated HTMT ratio value is lower than the [3] standard of 0.85 , indicating that discrimination is confirmed between the constructs.

Table 2. Descriptive Statistics and Discriminant Validity of the Constructs

\begin{tabular}{|c|c|c|c|c|c|}
\hline \multirow[b]{2}{*}{ Construct } & \multicolumn{3}{|c|}{ Descriptive Statistics } & \multicolumn{2}{|c|}{ HTMT Ratio Value } \\
\hline & $\begin{array}{l}\text { No. of } \\
\text { Items }\end{array}$ & Mean & Standard Deviation & Attitude & Intention \\
\hline Attitude & 11 & 3.832 & 0.654 & & \\
\hline Intention & 6 & 3.725 & 0.668 & 0.836 & \\
\hline
\end{tabular}

Assessing the Structural Model

Since the measurement model is reliable and valid, we test the structural model at this stage by following [20] recommended 5-step procedure. The first step of checking multicollinearity is irrelevant since there is only one predictor of the tested model. Secondly, through bootstrapping process with 5000 resample, the path coefficient was examined. Table 3 depicts a positive relationship exists between attitude and intention $(\beta=0.745, \mathrm{t}=23.923, \mathrm{p}<$ 0.001). Therefore, H1 is supported. In the next step, the explanatory power of the tested model was inspected through $\mathrm{R}^{2}$ value. Table 3 demonstrates that 55.6 percent of the variation in the intention to purchase is accounted for the variation in the attitude of the consumers. Fourthly, as recommended by Cohen [19], the effect size was calculated which indicates a significant role of attitude on intention to purchase (see Table 3). Finally, following suggestion by Henseler, Ringle, and Sinkovics [5], the predictive relevancy of the model was also examined. Table 3 indicates that the predictive relevancy of the model is medium [16] as shown in figures 1 and 2.

Table 3. Outputs of the Structural Model

\begin{tabular}{|c|c|c|c|c|c|c|c|c|c|c|}
\hline Hypothesis & Relationship & & $\beta$ & SE & $\mathrm{t}$-value & $\begin{array}{l}\mathrm{p}- \\
\text { value }\end{array}$ & Supported & $\mathrm{R}^{2}$ & $\mathrm{f}^{2}$ & $\mathrm{Q}^{2}$ \\
\hline H1 & $\begin{array}{l}\text { Attitude } \\
\text { Intention }\end{array}$ & $\rightarrow$ & 0.745 & 0.031 & 23.923 & 0.000 & Yes & 0.556 & 1.25 & 0.276 \\
\hline
\end{tabular}




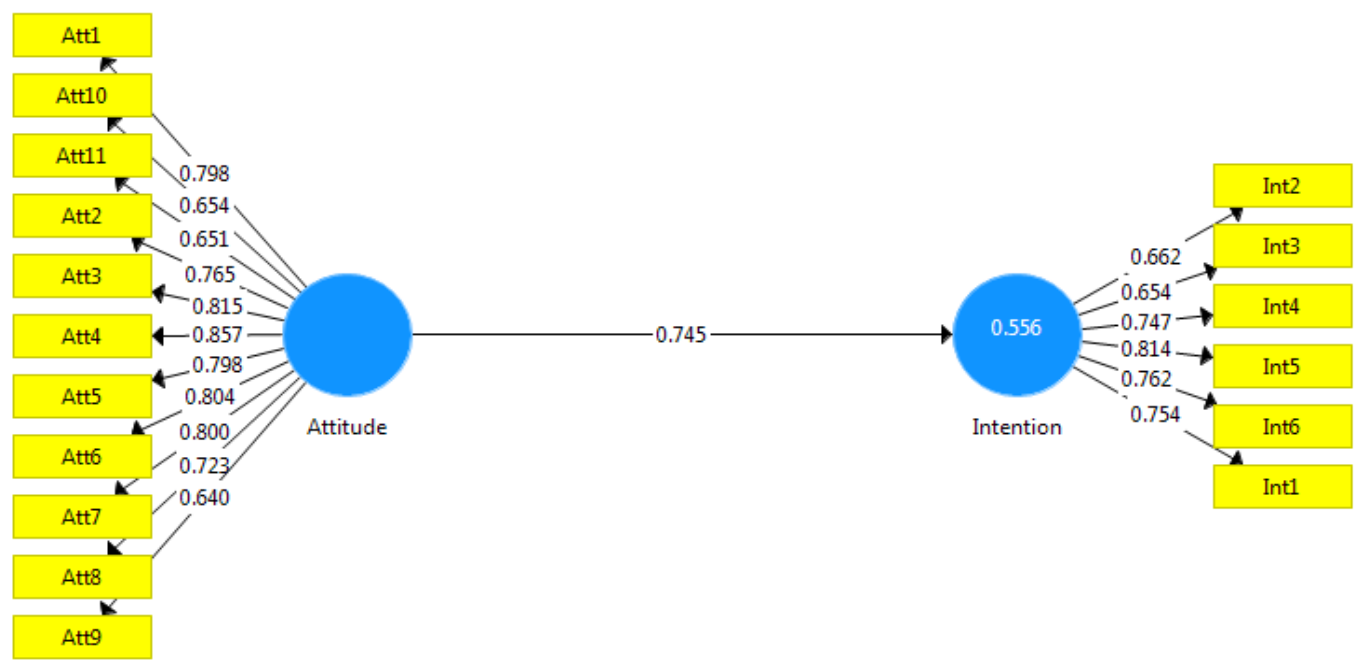

Fig 1. Results of the Measurement Model

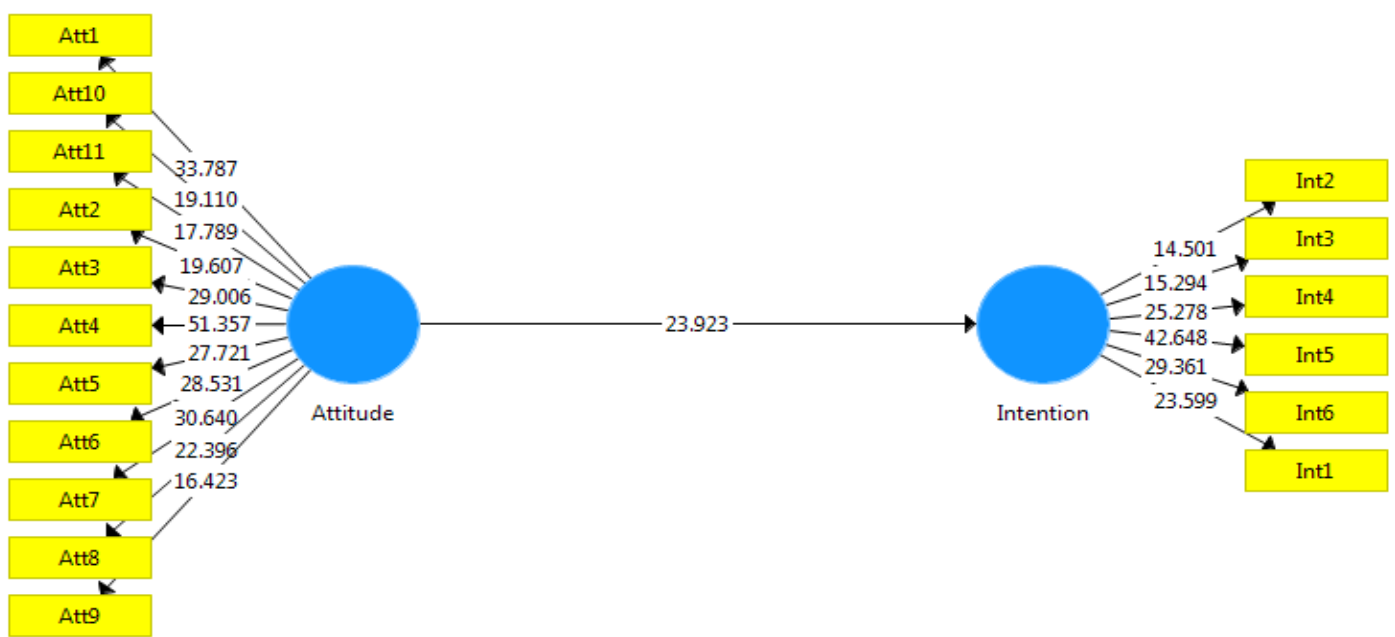

Fig 2. Results of the Structural Model

\section{V.DISCUSSION AND RECOMMENDATIONS}

This study has made an effort to justify the important role of attitude in promoting consumer's intention to purchase energy efficient vehicle. The analysis shows a positive relationship exists between consumer's attitude towards energy efficient vehicle and intention to purchase energy efficient vehicle. It demonstrates that the more customer develops favourable attitude towards energy efficient vehicle, the intention to purchase will be higher. Therefore, favourable consumer's attitude toward energy efficient vehicle contributes to consumers' intention to purchase energy efficient vehicle. This concurs with other studies in Malaysia by [1]; [2]; [5] and [5].

This finding is important to automobile manufacturers concerned with marketing EEV in Malaysia, give empirical support that they should concentrate on developing positive consumers' attitudes toward EEV. This could be realized through development of societal beliefs and perception towards the features of EEV, i.e the performance of EEVs is better than conventional vehicles. Although the Theory of Reasoned Action (TRA) proposes that in most cases, behavioural intention leads to actual behaviour, by promoting EEV test drives at local showrooms, clarifying the economic benefits of EEVs and focusing on the benefits of EEV on reducing the gas emissions, improving public health and minimizing ecological damage to consumers can build favorable attitudes, which then follows with decision to purchase EEVs. To accept EEVs as alternative to conventional vehicles, consumers need to be educated about the opportunities, benefits and practical advantages of using EEV. Consumers should also have a mechanism to evaluate and compare this green technology with conventional vehicle. 
We believe that there will be an increasing demand for EEV in the future, and Malaysian automobile manufacturers should grab this opportunity. Research on EEVs have been conducted few years back and their acceptance represents "a key plank" in the development of upcoming policies on sustainable energy.

\section{Limitations and future research suggestions}

The present study has few limitations which can be addressed by other researchers in future study. It should be noted that actual behavior was not tested in the research model. Whilst this is consistent with several prior studies, future research is recommended to incorporate the actual purchase of EEVs. The current study has shown that 55.6 percent of intention can be explained by attitude, which shows that there might be more variables that could probably influence consumers' purchase intention. Meaning to say that, there are 44.4 percent of differences that can be described by other constructs which were not tested in the present study. Therefore, future study can consider examining other possible predictors that can influence consumers' purchase intention of EEVs.

An extensive review of literature shows that attitude and intention is highly correlated. Based on this fact, the association between them examined at one point in time will not capture the accuracy as the results will depend on the time of their application. This shows that the examination of this relationship is better conducted through longitudinal studies.

As with other studies, this study's limitations are also present in its methodological aspects. Like other studies that employ quantitative research design, this study's respondents were asked for their perceptions of statements provided in the questionnaire, and such perceptions were gauged through a Likert scale. The respondents' answers may be influenced by their biased perception of the phenomenon. As such, this study proposes that future research can employ mixed research design (quantitative and qualitative research design) to complement each other.

\section{CONCLUSION}

The finding of the study recommends that consumer's favorable attitude towards energy efficient vehicle (EEV) has a significant influence on the intention to purchase EEV. The finding of the study served as an additional contribution to the knowledge of consumers' behavioral intention. This suggests that managers or marketers of EEVs should create more value if they want to be competitive and create consumers' favorable attitude towards energy efficient vehicle. The finding in this study supports previous studies in the same context. The recommendations are provided in order to give input from the view of consumers' intention to academicians and stakeholders.

\section{References}

[1]. W. Tian, Z. Liao, and J. Zhang, "An optimization of artificial neural network model for predicting chlorophyll dynamics," Ecological Modelling, vol. 364, pp. 42-52, Nov. 2017.

[2]. R. R. Ferdinand, "A Nonlinear Coupled Phytoplankton Dynamics Model," Numerical Functional Analysis and Optimization, vol. 23, no. 5-6, pp. 515-528, Jan. 2002.

[3]. Y. Wang and L. Li, "Li-ion battery dynamics model parameter estimation using datasheets and particle swarm optimization," International Journal of Energy Research, vol. 40, no. 8, pp. 1050-1061, Jan. 2016.

[4]. Q. A. Chaudhry and Q. M. Al-Mdallal, "Review of design optimization of fluid machinery: applying computational fluid dynamics and numerical optimization," Complex Adaptive Systems Modeling, vol. 7, no. 1, Jul. 2019.

[5]. S. Roy, S. Mukhopadhyay, and P. P. Sengupta, "Simulation Techniques on System Dynamics Modeling of Productioninventory Control Model," Journal of Information and Optimization Sciences, vol. 29, no. 1, pp. 17-28, Jan. 2008.

[6]. Z. MENG and H. IGARASHI, "Offline Design of Machine Dynamics using Individual Operation Model," The Proceedings of JSME annual Conference on Robotics and Mechatronics (Robomec), vol. 2019, no. 0, pp. 2A2-M04, 2019.

[7]. F. Feng, Z. Tang, and L. Wang, "A Fault Tolerance Optimization Model of the China Railway Geographic Network Topological Structure," Discrete Dynamics in Nature and Society, vol. 2015, pp. 1-8, 2015.

[8]. B. Liu, X. Mei, H. Jiang, and L. Wu, "A Nonpenalty Neurodynamic Model for Complex-Variable Optimization," Discrete Dynamics in Nature and Society, vol. 2021, pp. 1-10, Feb. 2021.

[9]. L. Plachel, “A unified model for regularized and robust portfolio optimization," Journal of Economic Dynamics and Control, vol. 109, p. 103779, Dec. 2019.

[10]. H. Chen, Y. Zhu, K. Hu, and X. He, "Hierarchical Swarm Model: A New Approach to Optimization," Discrete Dynamics in Nature and Society, vol. 2010, pp. 1-30, 2010.

[11]. L. Wang, Y. Qin, J. Xu, and L. Jia, “A Fuzzy Optimization Model for High-Speed Railway Timetable Rescheduling,” Discrete Dynamics in Nature and Society, vol. 2012, pp. 1-22, 2012.

[12]. X. Feng, Y. Zhang, Y. Li, and W. Wang, "A Location-Allocation Model for Seaport-Dry Port System Optimization," Discrete Dynamics in Nature and Society, vol. 2013, pp. 1-9, 2013.

[13]. Q. Yan, Q. Zhang, and X. Zou, "A Cost Optimization Model for Multiresource Leveling Problem without Project Duration Constraint," Discrete Dynamics in Nature and Society, vol. 2016, pp. 1-8, 2016.

[14]. D. Ying, "Optimization of Tourism Real Estate Development Project Based on Option Premium Model," Discrete Dynamics in Nature and Society, vol. 2021, pp. 1-8, Aug. 2021.

[15]. J. D. Amato and T. Laubach, "Estimation and control of an optimization-based model with sticky prices and wages," Journal of Economic Dynamics and Control, vol. 27, no. 7, pp. 1181-1215, May 2003. 
[16]. Y. Li, Y. Huang, and Y. Zhou, "Optimization of the Actuarial Model of Defined Contribution Pension Plan," Discrete Dynamics in Nature and Society, vol. 2014, pp. 1-7, 2014.

[17]. C. A. Ocampo and R. Mathur, "Variational Model for Optimization of Finite-Burn Escape Trajectories Using a Direct Method," Journal of Guidance, Control, and Dynamics, vol. 35, no. 2, pp. 598-608, Mar. 2012.

[18]. H. Pan and Z. Liu, "A Queuing Network Based Optimization Model for Calculating Capacity of Subway Station," Discrete Dynamics in Nature and Society, vol. 2017, pp. 1-7, 2017.

[19]. E. Selerio and R. Maglasang, "Minimizing production loss consequent to disasters using a subsidy optimization model: a pandemic case," Structural Change and Economic Dynamics, vol. 58, pp. 112-124, Sep. 2021.

[20]. L. Zhu, X. Wang, Z. Zhang, and C. Lei, "Spatial dynamics and optimization method for a rumor propagation model in both homogeneous and heterogeneous environment," Nonlinear Dynamics, vol. 105, no. 4, pp. 3791-3817, Aug. 2021. 